https://helda.helsinki.fi

\title{
The practice of 'mediation' in English as a lingua franca interaction
}

\section{Hynninen, Niina}

2011

Hynninen , N 2011 , ' The practice of 'mediation' in English as a lingua franca interaction ', Journal of Pragmatics , vol. 43 , no. 4 , pp. 965-977 . https://doi.org/10.1016/j.pragma.2010.07.034

http://hdl.handle.net/10138/230261

https://doi.org/10.1016/j.pragma.2010.07.034

acceptedVersion

Downloaded from Helda, University of Helsinki institutional repository.

This is an electronic reprint of the original article.

This reprint may differ from the original in pagination and typographic detail.

Please cite the original version. 
Final version of

Hynninen, Niina (2011) The practice of 'mediation' in English as a lingua franca interaction. Journal of Pragmatics, 43(4), 965-977. <doi:10.1016/j.pragma.2010.07.034>

\title{
The practice of 'mediation' in English as a lingua franca interaction Niina Hynninen*
}

\author{
Department of Modern Languages, English Philology, P.O. Box 24, FI-00014 University of Helsinki, \\ Finland
}

\begin{abstract}
This paper investigates the mechanisms of mediation in an English-medium university seminar course. Mediation refers to a form of speaking for another where a co-participant starts rephrasing another participant's turn that was addressed to a third party. The paper sets out to investigate mediation in multiparty interaction. It adopts a situated approach and combines analysis of university seminar course interaction with interview data. The findings suggest that mediation occurs frequently in the university course analysed and that the institutional practices of the course influence the practice of mediation: the course teachers take on the role of an intermediary. Mediation seems to have three main functions: 1) It facilitates understanding between participants. By providing alternative ways of expressing the same thing, intermediaries help participants to take part in the discussion. 2) Mediation organises discourse, and it is a way for the teachers to manage interaction. 3) It also has a socialising function in that it can include evaluation of students' contributions. Mediation is a means to engage participants who otherwise may not be able to participate in the interaction, and thus serves as a useful co-operation strategy.
\end{abstract}

Keywords: English as a lingua franca; Other repair; Mediation; Speaking for another

\footnotetext{
* Tel: +358-9-19122498

E-mail address: niina.hynninen@helsinki.fi
} 


\section{Introduction}

To keep up with the internationalisation of academia, universities are anxious to attract more and more international students and teachers by increasing the number of international English-medium study programmes. A recent survey (Wächter, 2008) of such programmes in European universities in non-English speaking countries indicates that between the years 2002 and 2007 there was a threefold increase in the number of these programmes. The kind of academic mobility we are talking about provides unprecedented opportunities for the exchange of ideas and knowledge, but it also causes concern about, for instance, declining standards of teaching due to participants' inadequate command of English, negative attitudes towards the language, and the question of local languages undergoing domain loss (e.g. Preisler, 2008, Kirkpatrick, 2009:254-255). It is clear that we should not disregard the doubts that the spread of English in academia is causing; however, it is equally important to consider how the participants themselves deal with this new situation. International students have sought an international education for themselves, and are aware of having to use English in their studies. But how do they manage to communicate in their English-medium courses?

To seek answers to this question, this paper explores communicative interaction in an international seminar course where the participants do not share a first language. In the course, speaking for another plays an intriguing role in the management of discourse. The investigation focuses on the practice of mediation, a form of speaking for another where a coparticipant intervenes in the course of the interaction by rephrasing another participant's turn that was addressed to a third party (sections 1.1 and 1.2). Since mediation can only occur in interactions with at least three participants, this paper investigates polylogues. The aim is to examine the forms that mediation takes and how it functions in interaction by exploring the following questions:

- How does mediation organise the interaction?

- What functions does it have in the interaction?

- What factors can influence its occurrence in the interaction?

In the following sections, mediation is discussed in more detail: first, it is approached as a form of speaking for another (section 1.1) and second, as a form of conversation analytic repair (section 1.2). The paper then turns to considering interactional settings, with a focus on English as a lingua franca (ELF) communication (section 2). Section 3 describes the data, and 
the approach adopted in this paper, and the analysis and discussion follow in section 4 . The study forms a part of an ongoing project called Studying in English as a Lingua Franca, or $\mathrm{SELF}^{1}$, at the University of Helsinki.

\subsection{Mediation as a form of speaking for another}

In multiparty interactions, participants sometimes speak for another participant, as the following quotation implies:

what $((.)$.$) your fellow student would like to know is$

This means that a speaker formulates his or her turn from the perspective of another participant, thus "taking the role of the other" (Schiffrin, 1994:131). Speaking for another can take different forms: a participant may, for instance, clarify or explain another participant's answer to the others, answer on someone's behalf or step in for another participant by rephrasing what someone else has just asked from a third person. This last form of speaking for another is interactionally interesting, since it points to situations where a co-participant feels the need to intervene with the course of the interaction. In this sense it resembles what conversation analysts call repairs, but it is the "third" participant who does the repair work (section 1.2). This form of speaking for another is here referred to as mediation to emphasise its intermediary function: when mediating, a speaker is positioned between two participants.

The term mediation is thus used to refer to a form of speaking for another, where a coparticipant starts rephrasing another participant's turn that was addressed to a third party. When mediating, a speaker occupies an intermediary position between two other interactants, and in this role, speaks for another participant present in the interaction. In Goffman's (1981) terms, the speaker positions him- or herself as an animator of someone else's ideas. An intermediary is thus first and foremost a spokesperson for someone else (see Schiffrin, 1994:106-133 on speaking for another). It should be noted, though, that this is not what Tannen $(2007,2010)$ calls "ventriloquizing”, or instances in which speakers frame their speech to represent others' voices. In ventriloquizing, speakers seek to represent their own

\footnotetext{
${ }^{1}$ The SELF project is directed by Professor Anna Mauranen at the University of Helsinki, and it is funded by the University of Helsinki Funds for the three-year period of 2008-2010. The project takes a close-up view of English as a lingua franca by investigating interactional data along with observations, written course material and participant interviews. For further information on the SELF project, see Mauranen et al. (2010:187-188) and the project website http://www.eng.helsinki.fi/elfa/self.
} 
meaning by speaking in someone else's voice; whereas an intermediary rephrases a previous utterance in order to mediate between two speakers.

Knapp-Potthoff and Knapp (1986) use the term mediation when talking about nonprofessional interpreters who mediate between speakers of different languages, and who, as interpreters, speak for the other interactants. Their findings are based on encounters between German legal advisers and Turkish guest workers and their bilingual interpreters, and suggest that the interpreters often become mediating third parties that need to deal with two different discourses: working as intermediaries between the other speakers on the one hand, and as participants in the interaction on the other (Knapp-Potthoff and Knapp, 1986:156-160). This dual role is seen to lead to partial failure of the encounters in that the interpreters are not always able to make the mediation such that the other participants' interactional goals would be achieved (ibid.). In interpreting, the interactants rely heavily on the interpreter, since they do not share a common code; whereas what is of interest in the present study is to see what happens when all the interactants share the language used for mediation.

By concentrating on mediation, we can learn about the ways participants orient to interaction: taking the role of an intermediary means taking responsibility for the progression of interaction. Also, mediation can shed light on the participants' orientations to each other's language use. But does mediation function as a means to engage others or is it rather a means to exercise authority? A focus on who mediates can further illustrate the interactional roles of the participants.

\subsection{Mediation as a form of repair}

Since mediation is a form of rephrasing someone else's words, it is related to what conversation analysts call repairs (e.g. Schegloff et al., 1977, Schegloff, 2000, Egbert, 2004). Repairs can be classified as either self- or other-initiated, which means that either the speaker (self-initiated), or one of the interlocutors (other-initiated) signals the need for repair. This is then followed by either self- or other-repair depending on the person who does the repair. A repair initiation expresses interactional "trouble" that needs to be solved before the interaction can continue, but although it implies that the prior turn was in some ways problematic, it does not necessarily indicate an error or mistake by the speaker. It may just as well indicate that the interlocutor, for instance, has difficulties in hearing what the speaker has just said or simply cannot grasp the point the speaker is trying to make. Similarly, a repair does not have to be a correction; rather it can mean, for instance, modification or confirmation of a prior contribution (Schegloff, 2000). 
To illustrate repair work done in interaction, let us take a look at the following data fragment (Extract 1; see section 3.1 for the data description).

\section{Extract 1}

$1 \quad \mathrm{~T} 2 \quad((\ldots))$ can you explain to us what is coconut

2 milk you know in all food recipes so you see

3 add coconut milk so what is the coconut milk Trouble-source turn

$4 \quad$ please tell us

5 S5 milk Repair-initiation

6 T2 milk coconut milk or coconut [cream] Repair

7 S5 [er] when you cut the coconut you (start er)

8 the water and is like er white water so it's

$9 \quad$ called coconut milk

10 T2 no this i wanted to correct you $((\ldots)))$

In the extract, we have a case of other-initiated self-repair. We can see that S5 initiates repair in line 5, which halts the conversation until the implied trouble in T2's turn (lines 1-4) is solved. The repair initiation is followed by T2's self-repair in line 6, after which S5 is able to give an answer to T2's question. A repair sequence thus halts the conversation until mutual understanding is restored, and the conversation can continue.

While there are two speakers in these types of repair sequences, the interactional data used in this paper includes several occasions of a third person taking part in the repair sequence, either after other-initiation of repair (section 4.1) or spontaneously (section 4.3). In these instances the third person does repair work by mediating between two speakers. In Extract 1, the repair in line 6 would thus have been done by a third person, rather than the speaker of the trouble-source turn. The interests of this paper thus fall primarily on otherinitiated repairs that are followed by repairs performed by a third person. Such repairs have interactional relevance: while self-initiated and self repairs reveal how speakers monitor their own speech, other-initiated and other repairs reveal interlocutors' reactions to a speaker's contribution. Also, with the intervention of the third person into the repair sequence, mediation draws our attention to the dynamics of multiparty, rather than dyadic interaction. This adds to our understanding of how repairs function in multiparty settings (see Egbert 1997). 
Before embarking on the analysis, let us consider the importance of the setting in influencing interactional practices, and discuss previous research done on ELF interactions.

\section{Interaction as a situated event}

Just as language users in general need to adapt their language to suit particular settings, speakers who use ELF need to learn to use English in specific environments. What makes ELF interactions particularly intriguing in this regard is their variability: the participants represent a variety of different lingua-cultural backgrounds, their command of English often varies, and the interactions can take place in different settings. For instance, Pölzl and Seidlhofer (2006) suggest that the setting where ELF is used has an effect on the participants' interactional behaviour. Their analysis of a discussion between four Jordanian students and an Austrian researcher interacting in English in Jordan showed that local interactional norms were foregrounded (Pölzl and Seidlhofer, 2006:173). In settings like these, where the majority of speakers represent the same lingua-cultural background and even interact in their home territory, it can be expected that the shared background affects the speakers' use of any language.

While Pölzl and Seidlhofer's (2006) findings may not be that surprising in this regard, they do focus our attention on the interactional environment. Blommaert et al. (2005:198) suggest that the environment can affect the participants' capacity to make use of their linguistic resources and skills, and impose on the participants specific requirements that they may fail to meet. However, as implied in the Pölzl and Seidlhofer (2006) study, we should also take into account that different interactional situations enable the participants to make use of different interactional resources. For instance, it seems that the institutional nature of the seminar interactions analysed in this paper partly enables mediation to occur in the first place (section 3.2). The course teachers used a chairperson practice, and since a chairperson is already required to organise the discourse by allocating speaking turns, and it is part of a teacher's role to intervene, acting as an intermediary may be a natural extension of these roles.

Although the setting can be said to restrict or enable the use of certain interactional practices, it is the participants who constantly negotiate what kind of linguistic conduct is acceptable in the specific context. For instance, Hülmbauer (2009) shows how supposedly "incorrect" items used in ELF interaction did not cause communicative turbulence in the situations where they occurred, but rather helped participants make sense of the interaction. Similarly, Meierkord (2006), Cogo and Dewey (2006) and Björkman (2008) illustrate the co- 
operativeness, and Mauranen (2006) and Kaur (2009) the lack of misunderstandings in ELF speech despite "non-standard" use of English. What is notable in this kind of ELF research is that language is analysed without preconceived ideas of normality (see Firth and Wagner, 1997a, 1997b, also Kasper, 2006). Although it can be assumed that ELF speakers differ in their use of linguistic resources, the speakers are not assumed to be deficient communicators. The research is not concerned with individual speakers' competences or lack thereof, but instead, it focuses on interaction, and on how the participants, together, establish mutual intelligibility in the interaction. Such research has the potential to challenge existing conceptions of successful language use in that interaction is analysed in its own right, rather than in relation to established conceptions of correctness that may have nothing to do with the success of particular interactions. In terms of mediation, we can say that mediation is successful if the parties to the mediation achieve mutual understanding, that is, if the intermediary is able to help the others achieve their communicative goals.

\section{Data and methods}

The present study starts from the above premises, and draws on discourse analysis, conversation analysis and ethnographic approaches. Following the conversation analytic tradition of showing the relevance of the phenomenon studied for the participants in the interaction (e.g. Drew and Heritage, 1992, Schegloff, 1997), the purpose is to show the interactional relevance of mediation for the interactants in the data. It is thus acknowledged that it is important to illustrate from the data how the participants orient to each other, the phenomenon studied, as well as the situation itself. However, in order to take participants' points of view and experiences into account, this paper draws on participant interviews when appropriate. Being a common practice in more ethnographic approaches to interaction, participant interviews are used to further ground the interactional analysis in the situational context by looking at the phenomenon from a different angle. With this situated approach, the paper seeks to depict a phenomenon that is important for ensuring smooth communication. The following sections describe the data used (section 3.1) and discuss its institutional characteristics (section 3.2). 


\subsection{The data: Seminar course interactions and participant interviews}

The data used in the analysis come from one English-medium master's level seminar course arranged at the University of Helsinki in 2008. Five of altogether seven sessions were audiorecorded and observed. The sessions consisted of an introductory session as well as sessions with individual student presentations and ensuing discussions. In total, this amounts to approximately seven and a half hours of naturally-occurring ELF speech, supported by field notes and written course material.

In the course, the students were supposed to write a 10-15 page report on a topic related to the course theme, and give a presentation of up to 30 minutes based on that report. The presentations were followed by comments and questions from the other course participants. Since mediation was found to occur in these discussions, they form the primary data of the present study.

There were two teachers in the course, a Finnish-speaking course leader and another teacher, bilingual in Swedish and Finnish, who frequently attended the course sessions ${ }^{2}$. The latter was the course leader's superior, but the two were close colleagues who collaborated in other courses as well, with either one taking the main responsibility and the other providing his expertise when relevant. The 11 international students represented seven different first languages: Arabic, Portuguese, Dinka, Spanish, Catalan, English and Twi. The two students with English as their first language (L1) were an L1 speaker of Canadian English ${ }^{3}$ and a bilingual in Twi and West-African English. No local students with Finnish or Swedish as their L1 had chosen to take part in the course. The students' backgrounds also varied according to their student status: there were both exchange and master's degree students present, as well as students pursuing doctoral degrees. In addition, the students' command of English varied, with some students having more trouble expressing themselves in English than others. The students tended to group according to nationality so that the students from the same country sat next to each other in class. The students also tended to use their first, or sometimes second, language when conversing with other students from the same country. The teachers used Finnish when addressing each other. During teaching, other linguistic resources in addition to English were only occasionally used. ${ }^{4}$

\footnotetext{
${ }^{2}$ To be precise, the teacher attended three of the five recorded sessions.

${ }^{3}$ This student chose not to participate in the study, and therefore his speech has not been analysed.

${ }^{4}$ There was, for instance, some code-switching into Finnish when terminology was discussed.
} 
While the primary data used in this paper come from the course interactions, interview data $^{5}$ are also exploited in order to bring out participant perspectives. Three student informants were interviewed to find out about their views on studying in English as well as their experiences and perceptions of using English in international settings. Two students (later referred to as S3 and S8) were first interviewed together while the course was still going on, and these two together with a third student (later referred to as S4) were interviewed again after the course had finished. The interviews were conducted in pairs/groups to increase possibilities for fruitful discussions, and to keep the situation as informal as possible. The teachers were interviewed individually after the course had finished. These interviews focused on the teachers' perspectives on and experiences of teaching international student groups in English. The interviews were semi-structured theme interviews, which allowed questions to be tailored to the interview situation. The interview data are drawn on when relevant in the analysis to explore how the participants perceive using English in international settings.

\subsection{Seminar interactions as institutional talk}

In conversation analysis, casual conversation is distinguished from institutional talk which is characterised by, for instance, restrictions in turn-taking practices, specific institution-relevant roles of the participants and special constraints on what is considered an allowable contribution in the interaction (e.g. Drew and Heritage, 1992, Raevaara et al., 2001). Heritage (2005:115-137) sums up the main distinctive features of institutional talk as relating to 1) turn-taking, 2) overall structural organisation, 3) sequence organisation, 4) turn design and 5) lexical choice. These features can also be found in the university course under scrutiny.

First, the turns in the course were allocated by the course leader acting as a chairperson as is characteristic of, for instance, chaired meetings. The course leader regulated the turntaking, which restricted the possibilities of the other participants to contribute to the interaction.

Second, the structure of the course sessions followed a similar pattern throughout the course, with the course leader starting each session with a greeting followed by practical matters and an introduction to the day's programme, after which he yielded the floor to one of the students. The student then delivered a presentation which was followed by a discussion chaired by the course leader. Another student presentation and a discussion based on that followed, with the course leader finally concluding the session. The interaction in the course

\footnotetext{
${ }^{5}$ The interviews I conducted together with Pirjo Surakka-Cooper, who also took part in the rest of the data collection.
} 
was thus organised according to this structure, which further regulated the turn-taking organisation.

Third, sequence organisation refers to the ways in which certain actions project certain responses, which is exemplified by the conversation analytic adjacency pair. If a speaker for instance asks a question, the recipient is expected to provide an answer. In the university course, this question-answer sequence was frequent, but it was sometimes interrupted by mediation (section 4). Mediation thus affected the sequence organisation in the course.

Fourth, turn design deals with the ways that participants design their turns and choose the actions that the turns are supposed to implement. Often in institutional interaction, highly practiced representatives of an institution converse with less practiced laypeople (Heritage 2005:128), and these different roles could be seen in this university course as well. The experienced teachers designed their turns to meet the needs of their students.

Finally, to exemplify lexical choices that illustrate the institutional nature of the interaction, suffice it to say that the teachers often used an institutional "we", thus indexing that they were speaking for an institution. We can thus see that the data fulfil most of Heritage's criteria for institutional discourse.

\section{The practice of mediation in the university course}

Mediation was used throughout the course when mutual understanding seemed to be at stake. What is notable was its frequent use by the teachers as a strategy to help students understand each other. The students themselves did not act as intermediaries, not even those students whose L1 was English. Considering the teachers' authority in the course in general, it may not be surprising that they were the ones to take on the role of an intermediary. It may also be argued that it comes naturally to teachers to intervene in situations where students seem to struggle. However, assuming the role of an intermediary is not self-evident. The teachers could also have chosen not to mediate: for instance, they could have asked the students to rephrase their own questions and comments.

The teachers had adopted a chairperson practice, which meant that the course leader allocated speaking turns. The restriction in the turn-taking practice affected the availability of speaker roles, which may also have affected the practice of mediation. Nevertheless, it does not explain it, since both of the teachers acted as intermediaries.

It also quickly became clear that the teachers were the ones to comment on and repair the students' language use. This may be explained by the teachers' senior academic status and 
experience in international communication. It suggests that the teachers considered it their responsibility to guide the students' language use, and that they were comfortable enough in using English to do that, which may have played a role in their willingness and ability to mediate. All this shows that the course was teacher-led, which influenced the interaction, and partly explains why mediation was done by the teachers, rather than the students.

The following sections explore the practice of mediation by discussing mediation after other-initiation of repair and the teachers' role as intermediaries (section 4.1), unsuccessful mediation (section 4.2), spontaneous mediation (section 4.3), and the participant reactions following mediation (section 4.4). The sections do not exemplify different types of the phenomenon, but rather seek to illustrate how it was used in the interaction. The structure and functions, as well as the significance of mediation are discussed in sections 4.5 and 4.6, respectively.

\subsection{Taking the role of an intermediary}

Extract $2^{6}$ exemplifies mediation after other-initiated repair. The extract is a typical example of mediation. A student (S3) has just given a presentation and another student (S7) asks her a question, but an intermediary (T1) is needed before an answer can be provided.

\section{Extract 2}

$1 \quad \mathrm{~S} 7: \mathrm{mhm}$ in reference to fire (suppression) there are some kind of organisation

2 like firemens <sic> or er forest people forest prevent or fight with fire

3 S3: $\quad \operatorname{sorry}(i ' m)$ [( $i$ don't understand $)]$

4 T1: [er well ] what the speaker would like to know is er

5 we-no not the speaker but the er your fellow student would like to know is

6 that is there an organisation

7 S3: $\quad \mathrm{mhm}$

8 T1: er or a system that that er that is operational in the sudan for fire suppression

9 are there guards or are there watch towers or or what kind of mechanisms are

10 there in place for fire suppression

11 S3: (er okay), er er you mean er or- organisation er

12 T1: yes [what th- for for inst- what what o-]

\footnotetext{
${ }^{6}$ In all of the examples given, T1 refers to the course leader, T2 to the accompanying teacher, and each student has been given an identity number with for instance $S 7$ always referring to the same student. The speaker code SU refers to an unidentified speaker. Italics is used to highlight parts discussed in the text.
} 
13 S3: [(in science in science or) ]

14 T1: what organisations are responsible (of) fire ( $\mathrm{r}$ - suppression) how are these 15 organisations present

16 S3: yeah

17 T1: present in the in in the field in a country like sudan which is which is a huge 18 huge area

19 S3: er er fao organisation and er, er the responsibility of er fighting er fires or fire 20 er in general er er er is er F-N-C or er forest fire cor- corporation in sudan er is 21 the responsible for fires or er any er topic related to fires

22 T1: er you see you mean forests national

In Extract 2, S7 asks a question (lines 1-2) that S3 is not able to follow. S3 initiates repair by indicating non-understanding in line 3 (sorry ( $i$ 'm $i$ don't understand)), and T1 then starts to rephrase S7's question (starting in line 4), thus acting as an intermediary between the two students. It seems that the mediation is prompted by the trouble in understanding expressed by S3. T1 mediates by indicating that he is speaking for S7 (what ((...)) your fellow student would like to know), after which he reformulates S7's question (starting in line 6) reusing the word organisation, and further explicates the matter by suggesting examples of fire suppression mechanisms. S3 picks up the word organisation (line 11) and asks for further clarification after which T1 continues explaining and elaborating the question (starting in line 12), to which $S 3$ then gives what seems to be a satisfactory answer (lines 19-21), followed by rechecking of terminology.

The extract exemplifies how the teacher takes on the role of an intermediary. As the chairperson and the course leader of the course, T1 was responsible for keeping the interaction going. From the extract, we can see that he takes a very active role in explaining S7's question to S3. T1 does not ask S7 to rephrase his question, but starts doing that himself, and continues explaining until S3 is able to provide an answer. In lines 6-10, T1 rephrases S7's question three times: first he formulates the question as is there an organisation er or a system that that er that is operational in the sudan for fire suppression with the synonym system given for the term organisation used by $\mathrm{S} 7$, then he moves on to provide examples of practices to prevent fire from spreading (are there guards or are there watch towers), and finally he ends by another rephrase with the word mechanisms replacing organisation (i.e. what kind of mechanisms are there in place for fire suppression). T1 recycles elements (organisation, fire suppression) from S7's turn, but modifies the question for his purposes by 
clarifying S7's question with the rephrasing and the examples. We are thus not only talking about repetition of elements, but rather using these elements as the starting point for the rephrasing, and as an anchor to tie the mediation to the original question (see Haddington, 2005:53-60 on dialogic syntax).

The rephrasing and the examples $\mathrm{T} 1$ gives seem to promote communicative clarity, in that the rephrasing $\mathrm{T} 1$ is doing increases the likelihood that $\mathrm{S} 3$ is able to pick up the meaning from at least one of the formulations. This supports findings in, for instance, Mauranen (2007) who concludes that so called co-operation and explicitness strategies are foregrounded in ELF discourse. Her study shows, among other things, that reformulations increase clarity and help avoid misunderstandings (Mauranen, 2007:257). When interviewed, S3 took up the same issue suggesting that mediation facilitates understanding:

in seminars for example T1 and T2 er (will) explain your question of er audience er after that maybe is er more clear (an-er to) answer

S3's comment suggests that she has experienced trouble in understanding other students in the course. In addition, it shows her awareness of the practice of mediation, and implies that she may even expect the teachers to mediate.

In increasing the explicitness of his contribution, T1 seems to consider S3's nonunderstanding a language problem. After S3's clarification question (line 11) where she uses the term organisation, however, T1 no longer needs to give synonyms or examples, and he no longer resorts to these means in rephrasing the original question. The extract thus shows that in ELF situations where people have differing command of English, it is difficult to judge what causes non-understandings, and solving the issue may take more than one clarification turn. The persistence of T1 in explaining S7's question nevertheless illustrates that it is not an option to let the question pass. Mediation thus functions here as a way to organise the communication in such a way that it does not break down. Here we may again refer to the chairperson practice, which seems to function as a way to monitor the interaction and reduce possibilities for let-it-pass practices (cf. Firth, 1996, House, 2003:558).

As third-person intervention, mediation can be face-threatening (Goffman, 1967, Brown and Levinson, 1987, Watts, 2003). Mediation focuses attention on communicative trouble that needs to be solved before the discussion can go on, and in this process, attention is drawn to a particular student's inability to understand another student, as well as the need for someone to intervene. In Extract 2, S3 herself admits trouble in understanding (line 3), which can be seen 
to threaten her positive ${ }^{7}$ face. However, as shown in Extract 2, the persistence of $\mathrm{T} 1$ to explain the question posed by S7 lets S3 remain the authority on the topic itself. T1's mediation thus represents Goffman's (1967:14) protective orientation towards saving S3's positive face. T1's turn also shows defensive orientation (Goffman 1967:14) towards his own negative face in that T1 frames the mediation by explicating that it is S3's fellow student (line 5) who asked the question, rather than himself. T1 thus positions himself as an intermediary, which allows the students to be the experts and which can further be seen as a means to socialise students to the academic community.

\subsection{Unsuccessful mediation}

While mediation most often succeeded in facilitating communication, sometimes it did not result in the desired conclusion. In Extract 3, it seems that S8, who is supposed to respond to his fellow student S7's question, is not able to follow the discussion. Although the teachers did tend to elaborate on the students' answers (section 4.4), answering for a student, as in this extract, was not a common occurrence.

\section{Extract 3}

1 S7: how to produce the gum in the branch the trees . er i mean er why (did) the tree 2 produce (this) gum ,

3 T1: ja <foreign> what

4 S8: (er)

5 T1: could you explain what the what the gum is an- an- and how does [the tree produce it]

7 T2: [why it exists ]

8 T1: [yeah]

9 S8: [okay], er the gum production is start to tapping, tapping tapping er of acacia

10 senegal by (songhi) < foreign> this is tool er used to

11 T1: maybe yo-maybe you could have some of the pictures that you had you had 12 had [er]

13 T2: [you] have to make a wound

\footnotetext{
${ }^{7}$ The notions of positive and negative face derive from Brown and Levinson (1987). Following O'Driscoll's (1996: 4) redefinition of the concepts, positive face is here understood as "the background-conscious (preconscious) desire that the universal need for proximity and belonging be given symbolic recognition in interaction". Negative face, then again, refers to "the background-conscious (preconscious) desire that the universal need for distance and individuation be given symbolic recognition in interaction" (O’Driscoll, 1996:4). Face thus refers to our desire to feel that our positive and negative wants are being or will be satisfied (ibid.).
} 
14 S7: a wound

15 T2: wound

16 S7: [(ah okay okay yeah)] <overlapping speech in the background>

17 S8: [(s- speak up) ] (er this is er start to) gum arabic in er first er tapping of

18 gum arabic er november between november and january and (it start to) gum

19 arabic in er tapping to branches of trees and this is taken er six weeks after

20 after six weeks er to start to co- er collections er er in the er more than (seven)

21 collection (of the) trees and also of this er collection er to take er three weeks,

22 T2: so in (a) sense it's it's a a reaction of the tree er to heal the wound

23 [one could say]

24 SU: [(mhm yeah) ]

25 T2: like resin in some (o-) other trees but remember this is completely different

26 compound it's polysaccharide poly- water soluble water soluble and ((...))

In the extract, S7 self-repairs his question (lines 1-2), after which there is a pause. This pause seems to signal a need for mediation, even though there is no verbal indication of nonunderstanding on the part of S8, to whom S7's question is addressed. T1 acknowledges the question $\left(j a^{8}\right.$ in line 3 ) and immediately starts rephrasing it, with T2 joining in (line 7) with the mediation towards the end of T1's turn. S8's answer (lines 9-10) is followed by T1 attempting to continue helping S8 by suggesting he use some of the pictures he had in his presentation slides (lines 11-12), whereas T2 answers for S8 ([you] have to make a wound, line 13). Apparently S8 does not register T2's answer, especially as he (in lines 17-21) continues explaining the tapping process instead of explaining how the tree produces the gum in the first place. After S8's turn, T2 starts to elaborate on the whole issue (starting in line 22).

Here we can see that mediation does not always produce the desired result. In lines 5-7, we can again observe the use of explicitation, with T1 rephrasing the original question by recycling elements (gum, produce) from S7's question, and T2 providing another way to express the same matter (why it exists). However, the answer S8 provides in lines 9-10 is beside the point, and the two teachers react differently to it, with T1 seeking to further explain the question, and T2 opting for the faster and perhaps easier solution of answering for S8.

\footnotetext{
${ }^{8} \mathrm{Ja}$ (pronounced as [ja:]) is a characteristic discourse marker used by both of the teachers in this course. In Swedish, ja means "yes" and it is used to answer in the affirmative. In Finnish, the word jaa is sometimes used similarly. However, it is also found in combinations such as no jaa ("well yes"), which often has the meaning "well, not really". In the data, ja seems to be used in the beginning of turns as an acknowledgement of the previous speaker's contribution.
} 
Although T2 eventually considers it more effective to end the mediation efforts, in the extract, both of the teachers mediate, which suggests that the chairperson practice alone cannot explain the occurrence of mediation in the course. In addition, the extract shows that at least sometimes the teachers knew the answers to the students' questions, and instead of mediating, they could have answered for the students. However, even in Extract 3 exemplifying unsuccessful mediation - the teachers' first option was to mediate.

The student group was likely to benefit from T2's choice for taking charge of the situation by first giving the answer (line 13), and later elaborating on the topic (starting in line 22). For instance, in line 16, S7 signals understanding after T2's intervention. However, Extract 3 also illustrates that T2's choice disrupts the communication by creating confusion on the part of S8, who is first given the opportunity to provide an answer, only to be pulled in different directions later on. It is also possible that having both of the teachers as mediators (lines 3-8) creates additional pressure for S8 to elicit the expected answer. Further, compared to Extract 2, where T1 persistently rephrases a student's question, and this way allows the other student to be an expert on the topic she has presented on, in Extract 3, T2's choice undermines S8's possibility to prove his knowledgeability. S8 is dismissed as an expert on his presentation topic, which threatens his credibility. Answering for S8 can thus be taken to threaten his positive face. It then seems that on this occasion, at least for T2, it is more important to ensure that the topics are treated in detail than to help an individual student to follow the discussion.

In his interview, $\mathrm{T} 1$ expressed similar concerns for covering enough ground during the course sessions. When asked about what he does if he notices that a student has not understood, T1 explained that

there is not much time to go into that. Actually, the conversation, then, it ends there, we have to keep going. So the topic can be repeated a couple of times and then the student either understands or does not understand, but we have to go on (own translation from Finnish).

Even though in Extract 3, T1 is the one who seeks to continue mediating, his comment exemplifies that he too is aware of the necessity of balancing between ensuring that one specific student understands and ensuring that enough ground is covered to serve the interests of the whole group. 


\subsection{Spontaneous mediation}

While mediation can take place after verbal indication of non-understanding (i.e. otherinitiated repair) as in Extract 2, or indeed after a pause as in Extract 3, it can also be used spontaneously. This is exemplified in Extract 4. S2 has asked S4 a question concerning marketing strategies and statistics of bee products. S4 first answers the part on statistics, to which $\mathrm{S} 2$ reacts by reminding him about the marketing issues. This is where Extract 4 starts.

\section{Extract 4}

$1 \quad$ S2: and then marketing marketing

2 S4: yes

3 S2: marketing

4 S4: [now]

$5 \quad \mathrm{~T} 1:$ [in ] eh ja <foreign> any any points on marketing

6 do you have do you have views how for instance how could ho- how

7 how marketing of honey and other products could perhaps be be encouraged

8 S4: yea- yes i do actually a- because since we have like (er nearest another) ((...))

The extract shows how spontaneous mediation seemed to be for T1. In line 1, S2 reminds S4 that he has not yet touched on the marketing aspects he asked about earlier, and even though S4 starts to answer the question (line 4), T1 takes the floor and rephrases the query slightly overlapping with S4's turn (lines 5-7). The extract exemplifies mediation that does not follow non-understandings, but takes place spontaneously without any indication of nonunderstanding or request for clarification. T1 filters a student's contribution even before it is taken up by another student. Here T1's mediation can perhaps be explained as a way of reminding the whole group what the topic was about. The contribution organises the discourse in focalising the topic. The intervention also allows the teacher to take charge of the situation.

\subsection{Elaboration after mediation}

In Extract 5, we have both of the teachers mediating between two students. S7 has just given a presentation and $\mathrm{S} 2$ asks him a question.

\section{Extract 5}

$1 \quad$ S2: mister chairman one more question 
2 T1: er to the topic

3 S2: yes

$4 \quad$ T1: yes please yeah [quickly]

$5 \quad \mathrm{~S} 2: \quad[\mathrm{er} \quad] i$ would like the $s p-$ the speaker to er

6 (in) his own er suggestion how to deal with the constraints

$7 \quad$ (of these worms and er maize diseases)

8 T1: er

$9 \quad$ S7: excuse me [(xx) ]

10 T1: $\quad$ [in what] sense

11 T2: (he asked) how to control the pests

12 S2: pest an-

13 S7: how to control

14 T2: [yeah]

15 S2: [and] diseases

16 S7: $\mathrm{mhm}(\mathrm{e}-\mathrm{w}-\mathrm{with})(\mathrm{xx}) \mathrm{mhm}$ erm mono- monogrowth is is very very difficult to

17 control the (the) $(\mathrm{xx})$ and the insects because the growth of the insects increase

18 exponentially but in if $i$ think if there are a mixed er crops $i$ - is better and the

19 biological control is $\mathrm{i}$ think $\mathrm{i}$ - is possible

20 T2: and it's correctly er emphasised that this is a serious problem think of locusts if

21 you locusts land on your maize maize field so so nothing can be done actually

22 there is absolutely nothing you can do(ne) millions billions of locusts land an-

23 on your field and then the striga the witch weed that you mention here is so

24 bad in sub-saharan africa (it) destroys crops or decreases the yields and it's

25 almost impossible to get rid of it witch weed striga para- parasitic plant in mi-

26 maize field

In the extract, S2 asks the chairperson for permission to speak (line 1), and then addresses S7 through the chairperson by referring to S7 as the speaker (line 5). This exemplifies the formality of the chairperson practice in the course, and implies that mediation may even be expected. In line 9, S7 other-initiates repair by implying that he has not been able to understand the question, which is then followed by what is an unfinished mediation turn by $\mathrm{T} 1$ and a complete mediation turn by $\mathrm{T} 2$. We can also see that $\mathrm{S} 2$ comes in to remind the teachers of the second part of his question (and diseases in line 15). After a confirmation 
check in line 13, S7 is ready to answer. The answer is then followed by an evaluative comment (correctly emphasised) and some elaboration by T2 (starting in line 20).

In addition to monitoring the students' answers, the teachers at times also elaborated on the topic afterwards. The elaborations included evaluative comments as in Extract 5, where T2's turn starting in line 15 begins with and it's correctly er emphasised that, referring to the correctness of what the student has said. The teachers' reactions also included clarification questions (as in Extract 2, line 22, you see you mean) and summarising statements (as in Extract 3, line 22, so in (a) sense), which mainly served the needs of the whole group in that they were used to focus on and clarify the course contents. While these reactions may not necessarily count as part of mediation as such, they tended to regularly follow mediation and reveal something about its success (or failure). The evaluation and elaboration in Extract 5 (lines 20-26) further suggests that the reactions served in socialising students to become experts in their field, in that the students were given feedback on their progress.

\subsection{Structure and functions of mediation}

Based on the data analysis, the structure of a mediation sequence can be summarised as follows, the stages given in parentheses being optional:

1. trouble-source ${ }^{9}$ turn by A

2. (other-initiation of repair by B)

3. rephrasing of A's turn by $\mathrm{C}$, i.e. mediation

4. reaction from $B$

5. (evaluation and/or elaboration of B's turn by $\mathrm{C}$ )

Since mediation was only done by the teachers of the course, the letters A and B refer to the students, and $\mathrm{C}$ to either of the teachers (i.e. the course leader/chair person or the accompanying teacher). When we look at the structure, we can see that a mediation sequence resembles a repair sequence in that A's turn is followed by an optional repair-initiation by B, which is then followed by other-repair by $\mathrm{C}$ in the next turn. Mediation may thus be considered a modified version of conversation analytic other repair. Further, it seems to function mainly as a "retroactive", or backward-looking repair, which occurs after a problem

\footnotetext{
${ }^{9}$ It should be noted that the turn by A becomes a trouble-source only retrospectively, after B has initiated repair or $\mathrm{C}$ has started to mediate.
} 
has been recognised (Mauranen, 2006:137). However, as we saw in Extract 3, mediation can also be used "proactively" to prevent possible non- or misunderstandings.

Compared to repair sequences in dyadic interactions, the most striking difference is the third-person intervention (see also Egbert 1997). Instead of letting A and B solve the interactional trouble, $\mathrm{C}$ steps in to mediate. It should also be noted that it may require two or more reformulations to reach stage 4 . The optional stage 5 is included in the mediation sequence, although it can also be considered a separate part following the whole sequence. Stage 5 ties closely with stage 3 in that those doing the mediating are those doing the evaluating and elaborating. Interestingly, the intermediaries can thus take charge of the discussion, after they have first enabled others to contribute. The evaluations also provide the analyst an opportunity to assess whether the mediation is considered successful by the interactants or not.

In all, mediation seems to function on three different levels: 1) facilitating understanding, 2) discourse organisation, and 3) socialisation. First, mediation enhances mutual intelligibility. It tended to occur when a student expressed trouble in understanding, or when s/he was seen to be experiencing communication problems. That the practice enhances mutual intelligibility was illustrated in the data extracts where, after the intervention of a teacher, the students were shown to have replied to questions they did not at first understand. Mediation thus evens out differences in the command of English, and helps to overcome nonunderstandings.

Second, mediation structures the interaction, or organises the discourse. Since the chairperson took on the role of an intermediary, mediation reinforced the turn-taking rules inherent in the chairperson practice. However, since the other teacher mediated, too, mediation was not defined by this practice. Rather, it was a way for the teachers to manage the interaction and prevent communication breakdown.

Third, mediation seemed to contribute to socialising the students into academic practices as well as the appropriate research field. Mediation reinforced the different roles of the students and teachers. In evaluating the relevance and importance of the students' contributions, the teachers were able to direct the students' attention to what they considered important. What is more, by mediating, the teachers showed an example for the students in how to go about solving interactional trouble generally in a face-saving way. 


\subsection{Explanations for and significance of mediation}

If we now return to some the characteristics of institutional talk (Heritage, 2005:115-137) discussed in section 3.2, we notice that mediation functioned as a part of the institutional discourse. A mediation sequence tended to include a student asking a question which projected an answer from another student. This adjacency pair was interrupted by an optional repair-initiation of the student who was supposed to answer the question, and the mediation turn by one of the teachers, which can be likened to other-repair. While mediation thus disrupted the question-answer adjacency pair, it merely postponed the second pair-part. Mediation thus supported the sequence organisation by inserting a repair sequence - which was needed to overcome communicative trouble - between the question-answer adjacency pair.

Mediation partly reinforced the specific turn-taking practice in that the chairperson took on the role of an intermediary. The other teacher's intermediary role, however, disrupted this, and rather reinforceed the divide between the teachers and the students. This implies that the difference in institutional status is likely to have influenced mediation practices. Moreover, the different roles of the teachers and the students are best explained by the institutional context, which grants the teachers the right and duty to intervene in the interaction. $\mathrm{T} 1$ had a dual role in that he was both the course leader and the chairperson of the course, but this did not stop T2 from mediating as well. This can be explained by the two teachers' close cooperation in this and other courses, where they tended to share responsibilities, or even T2's prominent institutional status. That both of the teachers acted as intermediaries also suggests that, in terms of mediation, the teacher/expert role is more important than the chairperson role.

Both of the teachers were experienced users of ELF, and seemed to be able to adjust to their interlocutors' English: they did not need to ask students to clarify their questions before they started to mediate. What is more, their mediation efforts were most often successful, and they were able to design their turns so that the student who the question was posed to could finish the question-answer sequence.

The experience of the teachers in mediating can be seen in the way they were able to both recycle elements from the previous turn (i.e. the trouble-source turn) and add new elements to increase the possibility of mutual understanding. It seems that the extensive experience of the teachers in international communication had provided them with tools to mediate. The following quotation from T2's interview exemplifies the multitude of his previous international contacts: 
I've learned Thai English, Chinese English and Indian English. These variants I master pretty well and I can understand them ((...)) Then if the Chinese person does not understand what I'm saying, I have to change my speech into simple language or use more Chinese grammar in the language before the message gets through (own translation from Finnish)

The teacher is clearly aware of the multitude of Englishes as well as the importance of accommodating his listening and his speech according to his interlocutor. As seen in Extracts 3 and 5, he also made use of these skills when mediating between the students. Then again, the students may not have had much contact with different ways of using English, and consequently their accommodation skills were still developing. This kind of imbalance between participants is typical in institutional interaction (Heritage 2005:128), and the sheer difference in experience also seems to have influenced mediation practices. It is also possible that, since the teachers took such an active role in mediating between students, the students had learned to rely on the teachers as facilitators and did not invest in communicative work as much as they otherwise would have. This further reinforces the teacher-student divide.

At the same time that the institutionality of the discourse restricted the interaction especially in terms of turn allocation, it also seems to have had an enabling function: the teachers' role as intermediaries enabled students by giving them voice in a situation where they otherwise may not have been able to contribute. In this sense, mediation also functioned as a face-saving device, as we saw in Extract 2. In this university course, the participants, with the teachers at the forefront, can thus be seen to have overcome communicative trouble by making use of mediation.

It seems that the institutional nature of the course played an important role in determining who can take on the role of an intermediary. It is also possible that the teachers in this course prove to be exceptional in their ability and willingness to mediate between students, which means that the findings need to be tested against other material. Especially the frequent use of mediation in this course may well be exceptional. However, it would be surprising not to find mediation in other ELF interactions as well, and indeed, in discussing interactive repair sequences, Mauranen (2006:137-138) takes an example from an ELF interaction where we have a structure similar to the mediation analysed in this paper. A part of the example is reproduced below as Extract 6 with added line numbering:

\section{Extract 6}


$1 \quad$ S1: eh if you think eh that NATO has a future it doesn't [(xxxx)]

2 S2: [we need it or we don't]

3 S1: we need it or we don't thank you

$4 \quad$ S2: we need it or we don't (.) according to your opinion

$5 \quad$ S3: my country eh we came $(\mathrm{xxx})$ and eh wanted eh to access NATO

(Mauranen, 2006:137, own italics)

In the extract, $\mathrm{S} 1$ is trying to ask $\mathrm{S} 3$ a question. Apparently $\mathrm{S} 1$ is searching for an expression and S2 decides to come to his assistance in line 2. After S1 then completes his question, S2 starts mediating in line 4, possibly prompted by S1's search for expression. Mediation is thus used here as a co-operative strategy, much as in Extracts 2-5.

\section{Conclusion}

With the focus on one international university course, this paper has addressed the practice of mediation as a situated interactional activity. Mediation turned out to serve as a co-operative strategy that increases communicative explicitness and allows the interaction to proceed. Three main functions of mediation were discerned. First, mediation facilitates mutual understanding in engaging participants who otherwise may not have been able to contribute. Second, it functions as a discourse organising device. It was found to support and reinforce the institutional teacher-student divide and to help to keep the interaction going. The third function relates to socialisation practices.

To gain more insights into the mechanisms of mediation, it would be important to investigate interactions where institutional conventions do not play such a prominent role, or where the participants consist of, for instance, students only. Such studies could shed light on what factors contribute to taking the role of an intermediary when institutional roles do not restrict the choice. It would also be interesting to see whether L1 speakers of English use mediation for similar purposes. If they do, this would suggest that mediation is more of an institutional facilitating strategy than something that derives from the sometimes assumed inherent problematicity of ELF encounters.

As previous research suggests (e.g. Cogo and Dewey, 2006, Mauranen, 2006, 2007), explicitness as a strategy of social interaction seems to be common and useful in ELF encounters. Since mediation was found to increase explicitness, it thus seems to be a valuable strategy to be used in ELF encounters. Just like repairs, mediation may be necessary to avoid 
communication breakdown, and, similarly, it also slows down interaction in that it is an intervention in the course of the interaction. However, it was shown that mediation is an effective way to engage students, and to provide them with an opportunity to act as experts. It thus usually functions as a face-saving device. Especially because of these enabling functions, and the ways mediation contributes to communicative success, it would be important to raise awareness of mediation and to teach future ELF users how to act as an intermediary.

\section{Acknowledgements}

I would like to express my warmest thanks to all my informants for their participation in the project, as well as to Pirjo Surakka-Cooper for collecting the data with me. I also thank Anna Solin and Anna Mauranen as well as the guest editor Beyza Björkman and the two anonymous reviewers for their invaluable comments on earlier versions of this paper.

\section{Transcription conventions}

The transcriptions use a slightly modified version of the SELF project transcription conventions (see http://eng.helsinki.fi/elfa/self). Special symbols that appear in the extracts are explained below.

$\begin{array}{llll}, & \text { pause } 2-3 \mathrm{sec} & \text { wo- } & \text { word left unfinished } \\ \cdot & \text { pause } 3-4 \mathrm{sec} & (\text { text }) & \text { uncertain transcription } \\ \text { C-A-P } & \text { capitals for spelling of letters } & (\mathrm{xx}) & \text { unclear speech } \\ \text { [ } & \text { overlapping speech begins } & ((\ldots)) & \text { speech omitted } \\ \text { ] } & \text { overlapping speech ends } & <\text { text> } & \text { transcriber's comments }\end{array}$

\section{References}

Björkman, Beyza, 2008. English as the lingua franca of engineering: the morphosyntax of academic speech events. Nordic Journal of English Studies 7 (3), 103-122.

Blommaert, Jan, Collins, James and Slembrouck, Stef, 2005. Spaces of multilingualism. Language \& communication 25, 197-216.

Brown, Penelope and Levinson, Stephen, 1987. Politeness: Some Universals in Language Usage. Cambridge University Press, Cambridge. 
Cogo, Alessia and Dewey, Martin, 2006. Efficiency in ELF communication: from pragmatic motives to lexico-grammatical innovation. Nordic Journal of English Studies 5 (2), 59 93.

Drew, Paul and Heritage, John, 1992. Analysing talk at work: an introduction. In Drew, P. and Heritage, J. (Eds.), Talk at Work. Cambridge University Press, Cambridge, pp. $3-$ 65.

Egbert, Maria, 1997. Some interactional achievements of other-initiated repair in multiperson conversation. Journal of Pragmatics 27 (5), 611-634.

Egbert, Maria, 2004. Other-initiated repair and membership categorization - some conversational events that trigger linguistic and regional membership categorization. Journal of Pragmatics 36 (8), 1467-1498.

Firth, Alan, 1996. The discursive accomplishment of normality: on 'lingua franca' English and conversation analysis. Journal of Pragmatics 26, 237-259.

Firth, Alan and Wagner, Johannes, 1997a. On discourse, communication, and (some) fundamental concepts in SLA research. The Modern Language Journal 81 (3), 285-300.

Firth, Alan and Wagner, Johannes, 1997b. SLA property: no trespassing! The Modern Language Journal 82 (1), 91-94.

Goffman, Erving, 1967. Interaction Ritual. Essays on Face-to-face Behaviour. Pantheon Books, New York.

Goffman, Erving, 1981. Forms of Talk. University of Pennsylvania Press, Philadelphia.

Haddington, Pentti, 2005. The Intersubjectivity of Stance Taking in Talk-in-interaction. Oulu University Press, Oulu.

Heritage, John, 2005. Conversation analysis and institutional talk. In: Fitch, K. L. and Sanders, R. E. (Eds.), Handbook of Language and Social Interaction. Lawrence Erlbaum Associates, Publishers, London, pp. 103-147.

House, Juliane, 2003. English as a lingua franca: a threat to multilingualism? Journal of Sociolinguistics 7 (4), 556-578.

Hülmbauer, Cornelia, 2009. 'We don't take the right way. We just take the way that we think you will understand' - the shifting relationship between correctness and effectiveness in ELF. In: Mauranen, A. and Ranta, E. (Eds.) English as a Lingua Franca: Studies and Findings. Cambridge Scholars Publishing, Newcastle upon Tyne.

Kasper, Gabriele, 2006. Beyond repair. Conversation analysis as an approach to SLA. AILA Review 19, 83-99. 
Kaur, Jagdish, 2009. Pre-empting Problems of Understanding in English as a Lingua Franca.

In: Mauranen, A. and Ranta, E. (Eds.) English as a Lingua Franca: Studies and Findings. Cambridge Scholars Publishing, Newcastle upon Tyne.

Kirkpatrick, Andy, 2009. English as the international language of scholarship: Implications for the dissemination of 'local' knowledge. In Sharifian, F. (Ed.) English as an International Language. Perspectives and Pedagogical Issues. Multilingual Matters, Clevedon, pp. 254-270.

Knapp-Potthoff, Annelie and Knapp, Karlfried, 1986. Interweaving two discourses - The difficult task of the non-professional interpreter. In House, J. and Blum-Kulka, S. (Eds.) Interlingual and Intercultural Communication. Discourse and Cognition in Translation and Second Language Acquisition Studies. Gunter Narr, Tübingen, pp. 151-168.

Mauranen, Anna, 2006. Signaling and preventing misunderstanding in English as lingua franca communication. International Journal of the Sociology of Language 177, 123150.

Mauranen, Anna, 2007. Hybrid voices: English as the lingua franca of academics. In: Flottum, K., Dahl, T. and Kinn, T. (Eds.), Language and Discipline Perspectives on Academic Discourse. Cambridge Scholars Press, Cambridge, pp. 244-259.

Mauranen, Anna; Hynninen, Niina and Ranta, Elina, 2010. English as an academic lingua franca: The ELFA project. English for Specific Purposes 29, 183-190.

Meierkord, Christiane, 2006. Lingua franca communication past and present. International Journal of the Sociology of Language 177, 9-30.

O'Driscoll, Jim, 1996. About face: A defence and elaboration of universal dualism. Journal of Pragmatics 25, 1-32.

Pölzl, Ulrike and Seidlhofer, Barbara, 2006. In and on their own terms: the 'habitat factor' in English as a lingua franca interactions. International Journal of the Sociology of Language 177, 151-176.

Preisler, Bent, 2008. Teaching in a foreign language: linguistic performance and academic authority in the international university. In: Haberland, H., Mortensen, J., Fabricius, A., Preisler, B., Risager, K. and Kjærbeck, S. (Eds.), Higher Education in the Global Village. Department of Culture and Identity, Roskilde University, Roskilde, pp. 103122.

Raevaara, Liisa, Ruusuvuori, Johanna and Haakana, Markku, 2001. Institutionaalinen vuorovaikutus ja sen tutkiminen. In: Ruusuvuori, J., Haakana, M. and Raevaara, L. 
(Eds.), Institutionaalinen vuorovaikutus. Keskustelunanalyyttisia tutkimuksia.

Suomalaisen kirjallisuuden seura, Helsinki, pp. 11-38.

Schegloff, Emanuel A., 1997. Whose text? Whose context? Discourse \& Society, 8 (2), 16587.

Schegloff, Emanuel A., 2000. When 'others' initiate repair. Applied Linguistics 21 (2), 205243.

Schegloff, Emanuel A., Jefferson, Gail and Sacks, Harvey, 1977. The preference for selfcorrection in the organization of repair in conversation. Language 53 (2), 361-382.

Schiffrin, Deborah, 1994. Approaches to Discourse. Blackwell, Oxford.

Tannen, Deborah, 2007. Talking Voices. Repetition, Dialogue and Imagery in Conversational Discourse. 2nd ed. Cambridge University Press, Cambridge.

Tannen, Deborah, 2010. Abduction and identity in family interaction: Ventriloquizing as indirectness. Journal of Pragmatics 42, 307-316.

Watts, Richard J., 2003. Politeness. Cambridge University Press, Cambridge.

Wächter, Bernd, 2008. Teaching in English on the rise in European higher education. International Higher Education 52, 3-4. Available at http://www.bc.edu/bc_org/avp/soe/cihe/newsletter/ihe_pdf/ihe52.pdf, (23 June 2010).

Niina Hynninen is a researcher in the SELF (Studying in English as a Lingua Franca) project at the University of Helsinki, Finland. Her main research interests include English as a lingua franca, interactional sociolinguistics and language regulation. She is currently working on her $\mathrm{PhD}$ thesis on mechanisms of language regulation in ELF interaction. 